\title{
SESSION $\mathbf{B}_{70}$
}

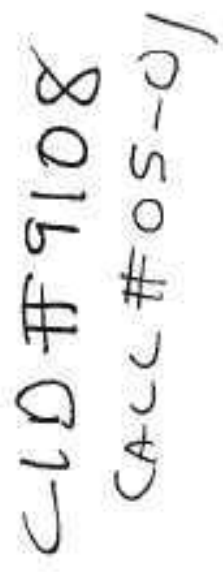

HIGH-VOLTAGE THERMIONIC REACTOR USING DOUBLE-SHEATH FUEL ELEMENTS

A. Schock

Fairchild Space and Electronics Division, Germantown, Maryland 20767, USA

3rd International Conference on

Thermionic Electrical Power Generation

Jülich, Federal Republic of Germany

June $5-9,1972$

I-: KERNFORSCHUNGSANLAGE JULICH GmbH 

HIGH-VOLTAGE THERMIONIC REACTOR USING DOUBLE-SHEATH

FUEL ELEMENTS

A. Schock

Fairchild Space and Electronics Division, Germantown, Maryland 20767, USA

\section{REVISED ABSTRACT}

A novel design concept for a "flashlight-type" in-core thermionic reactor is described. This concept, called the "double-sheath" design in contrast to the previously considered "wet-sheath" and "dry-sheath" concepts, permits the build-up of high reactor output voltages, without the danger of cesium breakdown and shorts-to-ground. In addition to a description of the design and its functional components, a brief discussion of suggested fuel element fabrication and reactor assembly techniques is presented. The proposed design offers the potential of high reliability because only insulators at very low potentials (e. g. $<3$ volts) are in contact with cesium vapor; because there are no ceramic or cermet seals within the reactor (all are outside, beyond the reflectors); and because all vacuumtight joints in the reactor are between ductile niobium components. 
HIGH-VOLTAGE THERMIONIC REACTOR USING DOUBLE-SHEATH FUEL ELEMENTS*

A. Schock

Fairchild Space and Electronics Division, Germantown, Maryland 20767, USA

\section{INTRODUCTION}

In thermionic reactor systems, particularly in the case of space power plants, reasonably high output voltages are desirable to facilitate power transmission and conditioning. Very low voltages result in relatively inefficient power conditioners requiring large low-temperature radiators, and lead to excessively high output currents requiring heavy transmission lines to reduce ohmic losses.

To minimize transmission losses and line weights, one is tempted to place the power conditioners as close to the thermionic reactor as possible, instead of locating them behind the radiators to take advantage of geometric attenuation of the incident nuclear radiation. But since the power conditioning devices are radiation-sensitive, placing them near the reactor would generally lead to highly undesirable increases in the size and weight of the required radiation shields. For these reasons, very low output voltages entail serious disadvantages.

The achievement of higher output voltages, however, is complicated by the danger of electrical breakdown through cesium vapor. In a "flashlight-type" thermionic reactor, the outer sheaths of all fuel elements operate at the common ground potential of the liquid metal coolant.** Therefore, potential differences within the fuel elements, i.e., between electrodes and sheath, will range up to at least half the reactor output voltage. Tests $[3,4]$ have shown that, at certain

* - Work supported by U. S. Atomic Energy Commission under Contract AT (49-15) 3063 .

**- This is not necessarily true in the case of thermionic reactors employing "external-fuel" diodes $[1,2]$. 
cesium pressures and typical operating temperatures, breakdown can occur at extremely low potential differences (e.g., < 5 volts). The resultant shorts-toground can seriously degrade, or even destroy, the reactor performance.

To circumvent this low limit on reactor voltage, a configuration we shall refer to as the "dry-sheath" design [e.g., 5] has been suggested, for physically separating the cesium vapor from the outer sheath. In previously proposed "dry-sheath" designs, that separation depends on the vacuum-integrity of a multiplicity of ceramic seals (one per diode) within each fuel element. Loss of any one of these internal seals would change the element from a "dry-sheath" to a conventional "wet-sheath", with breakdown currents limited only by the integrity of ceramic coatings. Since tests $[6,7]$ have shown that alumina exposed to prolonged irradiation by fast neutrons can undergo extensive swelling and degradation, these "dry-sheath" designs are still limited to undesirably low reactor voltages, with their previously mentioned disadvantages.

The present paper presents a third alternative, referred to as the "doublesheath" design. In this design, each fuel element is encased in two insulated metal sheaths: an outer sheath at ground potential, and an inner sheath at the potential of the ne gative terminal of the fuel element. The cesium vapor is completely enclosed within the inner metal sheath, whose insulator is subjected only to the low voltage produced by a single fuel element. The outer sheath insulator, which may have to withstand the full reactor voltage, is not subject to low-voltage breakdown, since it is not exposed to cesium vapor. There are no internal ceramic seals; all seals are outside the reactor, beyond the axial reflectors. Thus, the "double-sheath" design permits the attainment of high voltages, e.g., up to 150 volts per $100 \mathrm{ekw}$, with good reliability.

\section{ILLUSTRATIVE DESIGN}

The "double-sheath" design concept, the essence of which was briefly described in the Introduction, will be clarified by means of a specific illustrative design, including some discussion of possible fabrication and assembly methods. In reading this section, it is important to distinguish those features which are essential parts of the "double-sheath" concept from those which are merely included for clarity and illustrative completeness, but which could easily be replaced by improved alternatives.

One basic decision concerns the length of the thermionic fuel element (TFE): whether to extend it over the full height of the reactor core or only half the core height. In the latter case, which was chosen for our illustrative design, there is a mirror-image TFE in the opposite core half. Each TFE is joined to a header plate at its reactor end face, and the TFE's free ends meet at the reactor midplane. The choice of this option entails the disadvantage that the inner sheath must act as a current return lead from the TFE's free end, with a resultant ohmic loss. But it has the advantage of permitting very low TFE voltages without excessive diode lengths. 
The specific design described here will be illustrated in just three figures each containing considerable detail. Figure 1 depicts the design and construction of the thermionic fuel element; Figure 2 shows how the TFE's may be assembled to form the reactor core, including possible methods of making redundant seals to the header plates and high-conductance series connections between 'TFE's; and Figure 3 summarizes the entire design.

One distinctive feature of the proposed TFE design is that the collector assembly, consisting of sheaths, insulators, axial reflector, and all the collectors of the TFE, is fabricated as a single, complete unit. Only later are the fueled emitters inserted in place and joined to their adjacent collectors. This is in contrast to previous approaches, in which emitter-collector pairs are first fabricated as discrete subassemblies that are subsequently inserted into the outer sheath, using such methods as slip-fitting, swaging, or brazing.

An illustrative collector assembly for a five-diode TFE is depicted in Figure 1a. That same collector assembly equipped with a redundant metalceramic seal and loaded with its fueled emitters is shown in Figure $1 \mathrm{~b}$. And the complete TFE, with end caps and cesium reservoir, is shown in Figure 1c. The remainder of Figure 1 shows close-up views of various sections, as discussed below.

As shown by the cut-away section at the center of Figure $1 \mathrm{a}$, the active region of the collector assembly consists of five co-axial layers. From outside to inside, these are the outer sheath, the outer insulator, the inner sheath, the inner insulator, and the collectors (which are insulated from each other by axial spacers). Figure 1a shows that each collector and mating spacer has four interlocking tabs. As explained later, the collector tabs are subsequently joined to mating emitter leads; and the insulator tabs provide lateral support to the centering guides at the free end of each emitter.

The upper part of Figure 1a shows the axial neutron reflector, followed by the necked down region which after reactor assembly provides a plenum for transverse coolant distribution, a massive outer-sheath hub used to join the TFE to the header plate of the reactor and the TFE's collector terminal as well as its emitter terminal with its central cesium duct and integral cesium leg. Note that the TFE's collector terminal is joined to its inner sheath, which acts as a return lead from the bottom collector. As shown at the lower end of Figure 1a, there is no insulating layer separating the inner sheath from the last collector.

The conductive parts of the five-layer collector assembly would be made of refractory metal, most likely niobium because of its ductility, excellent weldability, and good thermal expansion match with the insulators of interest. These insulators may be either ceramics or cermets, such as niobium with alumina or yttria. 
One way of fabricating the five-layer assembly is to start with a central molybdenum mandrel, on which the interlocking collectors and insulating spacers are assembled. The insulating layers could be applied either as sleeves or in the form of plasma spray. After sealing the outer sheath with temporary end caps of niobium, the entire assembly is bonded by hot isostatic compaction in an inert gas autoclave. This technique produces excellent bonds, with minimum thermal resistance at the interfaces $[8,9]$.

After autoclaving and ultrasonic testing to verify bond integrity, the outside of the assembly is machined to size, the molybdenum mandrel removed chemically, and -- after suitable stress-relieving of the assembly -- the central hole is honed to its final dimensions.

In the collector assembly described above, the section of the inner insulator layer above the active region acts as a metal-ceramic seal of the cesium enclosure. Because of its considerable length, extending through the axial reflector, the coolant plenum, and the header plate, the insulator would have to experience considerable cracking before cesium loss would occur.

Nevertheless, it is proposed that a second, redundant seal be added, to enhance the reliability of the TFE. As will be seen, this second seal is only subjected to minimal radiation damage, since it operates outside the reactor, beyond the axial reflector. The seal could employ whatever materials and construction have proved most reliable in the past.

In the configuration illustrated in Figure 1d, thin-walled niobium sleeves are brazed to a ceramic ring with a $\mathrm{T}$-shaped cross-section. The niobium sleeve at the top of the seal is integrally joined to a thick-walled niobium flange. After the seal assembly is joined to the collector assembly by electron-beam welding, that flange acts as the TFE's positive terminal.

The completed collector assembly is now ready to receive its fueled emitters, two of which are shown in exploded close-up view in Figure $1 \mathrm{e}$. The specific design shown is merely illustrative; other alternatives are possible.

In the design shown, each emitter has four emitter leads at its upper end, and four centering tabs at its lower end. Adjacent emitters are separated by a thin ceramic or cermet wafer, to minimize electron leakage between their end faces. The geometric relationship of these components after assembly is shown in close-up view in Figure $1 f$.

After the five emitters are loaded into the collector assembly, as shown in Figure $1 \mathrm{~b}$, the curved shoes of the emitter leads are joined to the corresponding tabs of the next higher collector. These tabs were shown earlier in Figure 1a, Joining can be effected by vacuum furnace brazing, followed by ultrasonic testing for bond integrity. 
The bottom end of the fueled collector assembly can now be sealed, by electron-beam welding niobium end caps to the inner and outer sheaths. Three end caps are shown; one for the inner sheath, and two for the outer. The outer sheath has redundant end caps for added reliability since this is the most critical weld joint, being exposed to the liquid-metal coolant.

The configuration of the TFE's lower end after end-cap closure is shown in close-up in Figure $1 \mathrm{~g}$. Note that the bottom end cap has a re-entrant cavity. As illustrated later, this serves to provide lateral positioning to the free end of the TFE at the reactor midplane.

For illustrative purposes, the TFE is shown as having a low-temperature liquid cesium reservoir rather than an integral cesium-graphite reservoir. The components making up the cesium reservoir are shown above Figure $1 \mathrm{~b}$. Note that its side wall consists of an insulating trilayer structure, which permits cooling the reservoirs with an auxiliary low-temperature coolant loop at ground potential. The fully assembled and sealed reservoir is shown at the top of the TFE in Figure 1c, and in close-up view in Figure 1h. The latter also shows the redundant ceramic seal, the two TFE terminals, and the massive shoulder at which the TFE is joined to the header plate of the reactor.

It should be pointed out that all provisions for the venting of fission gases, either from the emitters or from the TFE, have been omitted from Figure 1 for the sake of clarity. Fission gases would be vented from the emitters into the cesium space, and from there either to space vacuum or to a low-temperature sorption chamber. The vent from the cesium chamber must be open enough to prevent excessive buildup of xenon and krypton pressure, yet constricted enough to avoid excessive cesium loss. Ideally, the cesium loss rate would be just balanced by the release rate of fission-product cesium from the fueled emitters. The above venting arrangement is identical to that used in "wet-sheath" TFE's. It is not as desirable as the arrangement in a properly functioning "dry-sheath" TFE, where the fission gases are physically separated from the cesium.

\section{REACTOR ASSEMBLY SEQUENCE}

Possible steps in assembling the THE's to form the complete reactor core are illustrated in Figure 2. Figure 2a shows the top of the completed TFE, ready to be inserted into its mounting hole in the header plate shown in Figure $2 \mathrm{~b}$. The header plate acts as the structural support of the TFE's in its core half, and serves to seal the liquid metal coolant from the outside vacuum.

A very important principle underlying the assembly sequence described below is that each step in the sequence can be performed simultaneously on all TFE's in the reactor half. In other words, if a given step requires making a particular electron-beam weld in a vacuum chamber, all TFE's can be thus welded during a single cycle in the weld chamber, by appropriately programmed 
motion of the movable table on which the core half is mounted. This is made possible by arranging the design so that all welds are made with the electron beam parallel to the TFE axes.

The above principle is very important because by eliminating the need for a separate pumpdown cycle for each TFE, it makes it practical to precede each assembly step with an extremely long pumpdown period including the pre-heating of the entire core structure to maximize outgassing before welding. This, together with the use of redundant weld joints to eliminate the possibility of single-point failure, should materially enhance the ultimate reliability of the reactor.

A further point to be noted about the proposed assembly procedure is that after each step, all weld joints made during that step would still be accessible for electron-beam repair if subsequent testing should reveal the need for such repair.

Figure 2c shows the top of the TFE inserted into its mounting hole, ready for the major weld joining the massive shoulder of the TFE's outer sheath to the header plate. After these weld joints on all TFE's have been completed and satisfactorily leak checked, it is desirable to add a second liquid-metal seal, for redundancy and enhanced reliability, to eliminate the possibility of singlepoint failure.

The redundant seal could be provided by means of a niobium seal ring of the type shown above the TFE in Figure 2c and inserted into place in Figure 2d. Two welds are required to make this seal. The ring's inner edge is electronbeam welded to the appropriate shoulder of the TFE, and its outer edge to the header plate.

After completing the set of redundant seals, high-conductance series connections are installed between TFE's. These are also joined by electronbeam welding, but in this case, of course, the joints need not be leaktight.

In the proposed arrangement illustrated in Figure 2, each series lead consists of two separate parts: a ne gative TFE lead, which attaches to the shoulder of the inner sheath, just below the redundant ceramic seal; and a positive TFE lead, which attaches to the flange at the top of that seal. This is necessary to enable all weld joints in the core-half to be made simultaneously without mutual obstruction.

The negative lead is shown floating above the TFE in Figure $2 \mathrm{~d}$ and dropped into position in Figure 2e. After all negative TFE leads have been joined to their respective inner sheath shoulders, the positive TFE leads--illustrated at the top of Figure 2f--are dropped into position, as shown in Figure 2g. The series connections are then completed by making circular welds between the positive lead and the redundant seal flange, and straight-line welds to join the 
negative and positive TFE lead segments. Cross-connections between parallel TFE's, which can have a much lower conductance since they normally carry no current, have been omitted from the illustrations to avoid confusion.

Although Figure 2 shows the negative TFE lead as consisting of a solid, relatively rigid body, its vertical member could be constructed of a more flexible multi-foil structure, if desired.

Inspection of Figures $2 \mathrm{c}$ through $2 \mathrm{~g}$ reveals the existence of rectangular windows between the necked-down region of the TFE's, just below the header plate. These windows provide the transverse flow passages at the reactor end faces, to distribute the liquid-metal coolant to the cusp-shaped ducts between TFE's.

Figure $2 \mathrm{~h}$ presents a close-up view of the proposed design at the reactor midplane. As shown, there is a relatively thin grid plate, which provides lateral support to the free ends of all TFE's in the reactor. The illustration shows the bottom end of the previously described TFE and the corresponding end of its mirror image from the opposite core half.

As shown, the grid plate has protruding cylindrical hubs, to mate with the previously mentioned cavities in the end caps of the TFE's. The sliding contact fixes the TFE's free end laterally, but not axially. In addition, the grid plate has cusp-shaped holes, which permit relatively unobstructed axial coolant flow through the core.

Finally, the design described above is summarized in Figure 3, which shows the interrelation of the previously described components. While the illustrations presented here have shown all TFE's loaded with diodes of equal length, this is not necessarily desirable. As explained in a companion paper in these proceedings [10], the use of variable diode lengths within each TFE, and variable numbers of diodes per TFE across the reactor, makes it possible to achieve uniform emitter temperatures throughout the core, without recourse to fuel zoning. This would offer potential advantages in improved electrical performance, increased fuel loading, and reduced critical size. The double-sheath TFE design is fully compatible with the electronic temperature-flattening concept.

\section{SUMMARY}

The double-sheath TFE design concept offers the following features:

- The inner insulators, which are exposed to cesium vapor, are only subjected to very low potential differences ( $<3$ volts).

- The outer insulators, which may be subjected to full reactor voltage, operate in vacuum. 
- This permits relatively high reactor output voltages, which is very desirable for power conditioning and transmission.

- There are no ceramic or cermet seals within the reactor; these are outside, beyond the reflectors.

- All joints within the reactor that must remain leaktight are electronbeam welds between niobium components.

\section{REFERENCES}

1. DAVIS, J.P., GRONROOS, H. G., "Uninsulated In-Core Thermionic Diode Concept", Proceedings of the Second International Conference on Thermionic Electrical Power Generation, Stresa, Italy, p. 237.

2. ABBATE, M.J., EISEN, C. L., RAAB, B., SCHOCK, A., "External-Fuel Thermionic Reactors", ibid p. 221.

3. FITZPATRICK, G., YATES, M., CHIN, J., "Electric Discharges in Cesium in the Sheath Region of Thermionic Fuel Elements", Gulf General Atomic Report GACD-10316(1971).

4. GELHAUS, F.E., SAMSTAD, G.I., WILKINS, D.R., DUNLAY, J.B., "Sheath Insulator Electrical Characteristics", Proceedings of the 1969 IEEE Thermionic Conversion Specialist Conference, Carmel, Cal, , p. 384.

5. YATES, M.K., et al, "Thermionic Fuel Element Development Program Status", Proceedings of the 1971 IEEE Thermionic Conversion Specialist Conference, San Diego, Cal, (1971).

6. KEILHOLZ, G.W., MOORE, R.E., ROBERTSON, H.E., "Effects of Fast Neutrons on Polycrystalline Alumina and Other Electrical Insulators at Temperatures from $60^{\circ}$ to $1230^{\circ} \mathrm{C}^{\prime \prime}$, Oak Ridge National Laboratory, ORNL-4678.

7. REICHELT, W.H., et al, "Radiation-Induced Damage to Ceramics in the EBR-II Reactor", Proceedings of the 1970 IEEE Thermionic Conversion Specialist Conference, Miami Beach, Fla., p. 39.

8. WEAVER, C.V., RANKEN, W.A., "Development of Pressure-Bonded Sheathed Insulators", Proceedings of the 1969 IEEE Thermionic Conversion Specialist Conference, Carmel, Cal., p. 347

9. WEAVER, C.V., "Developments in Pressure-Bonded Sheathed Insulators and Ceramic-to-Metal Seals", Proceedings of the 1970 IEEE Thermionic Conversion Specialist Conference, Miami Beach, Fla., p. 34

10. SCHOCK, A., "Electronic Temperature-Flattening of Thermionic Reactors", Proceedings of the Third International Conference on Thermionic Electrical Power Generation, Juelich, Fed. Rep. of Germany, p. 


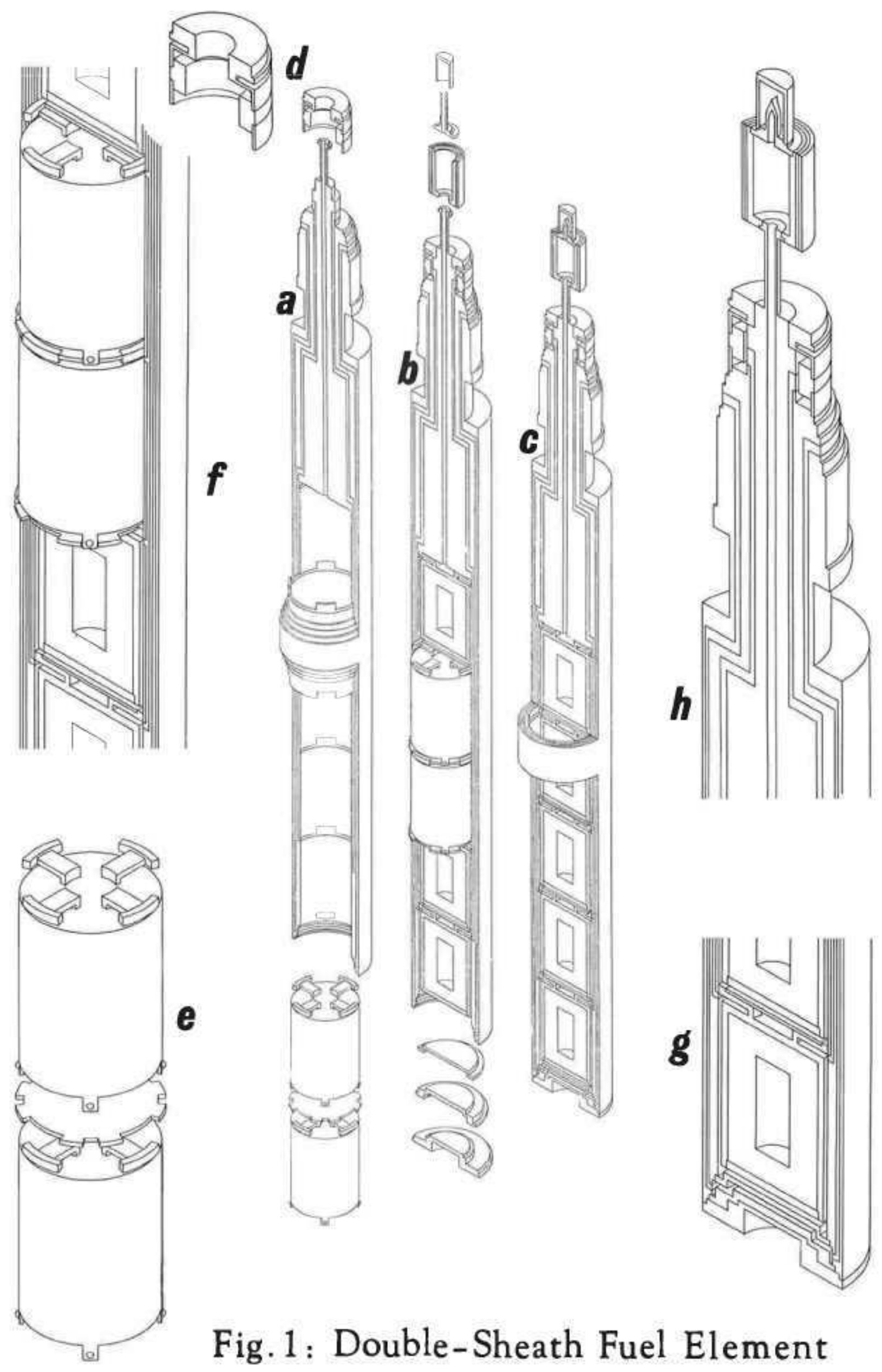




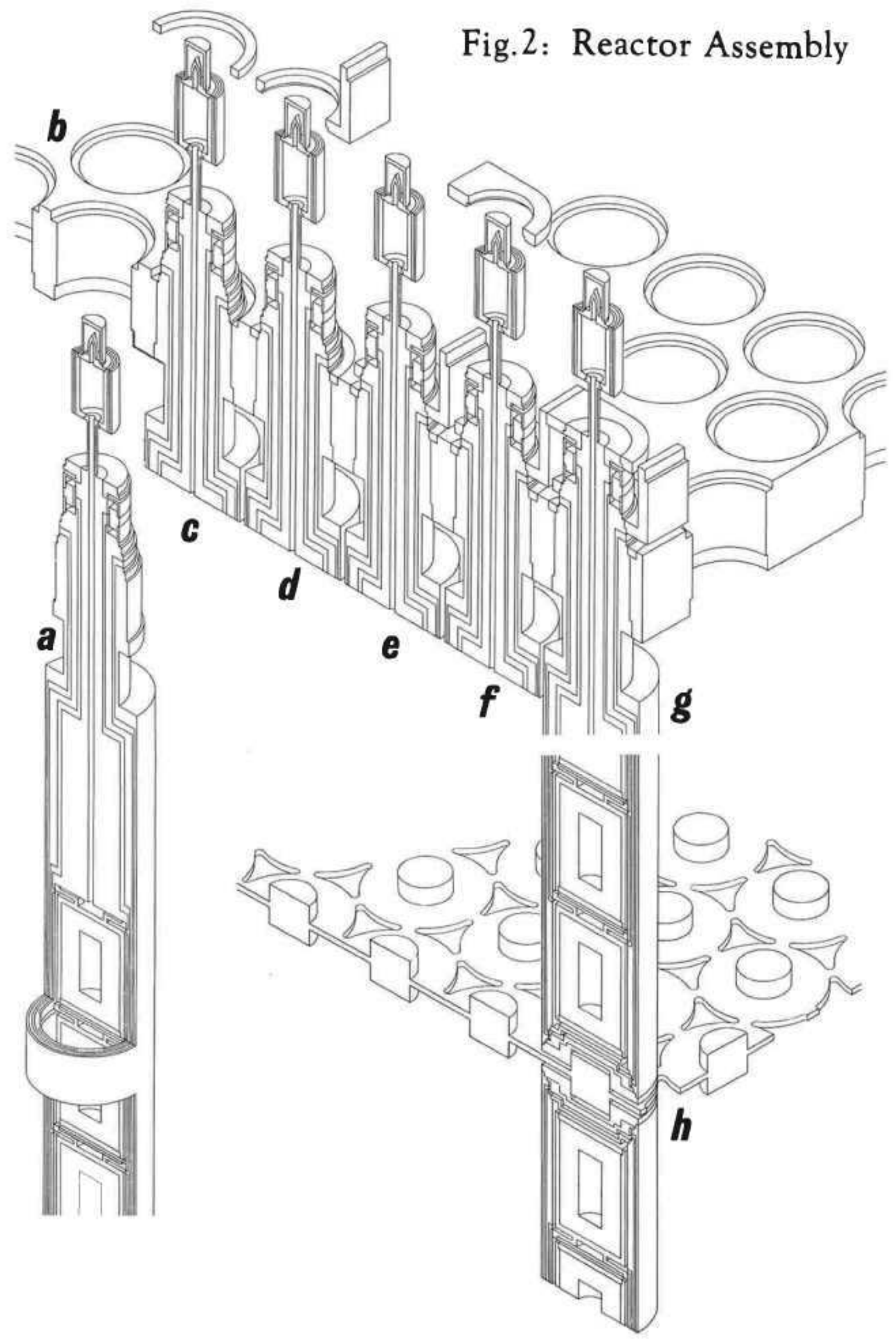




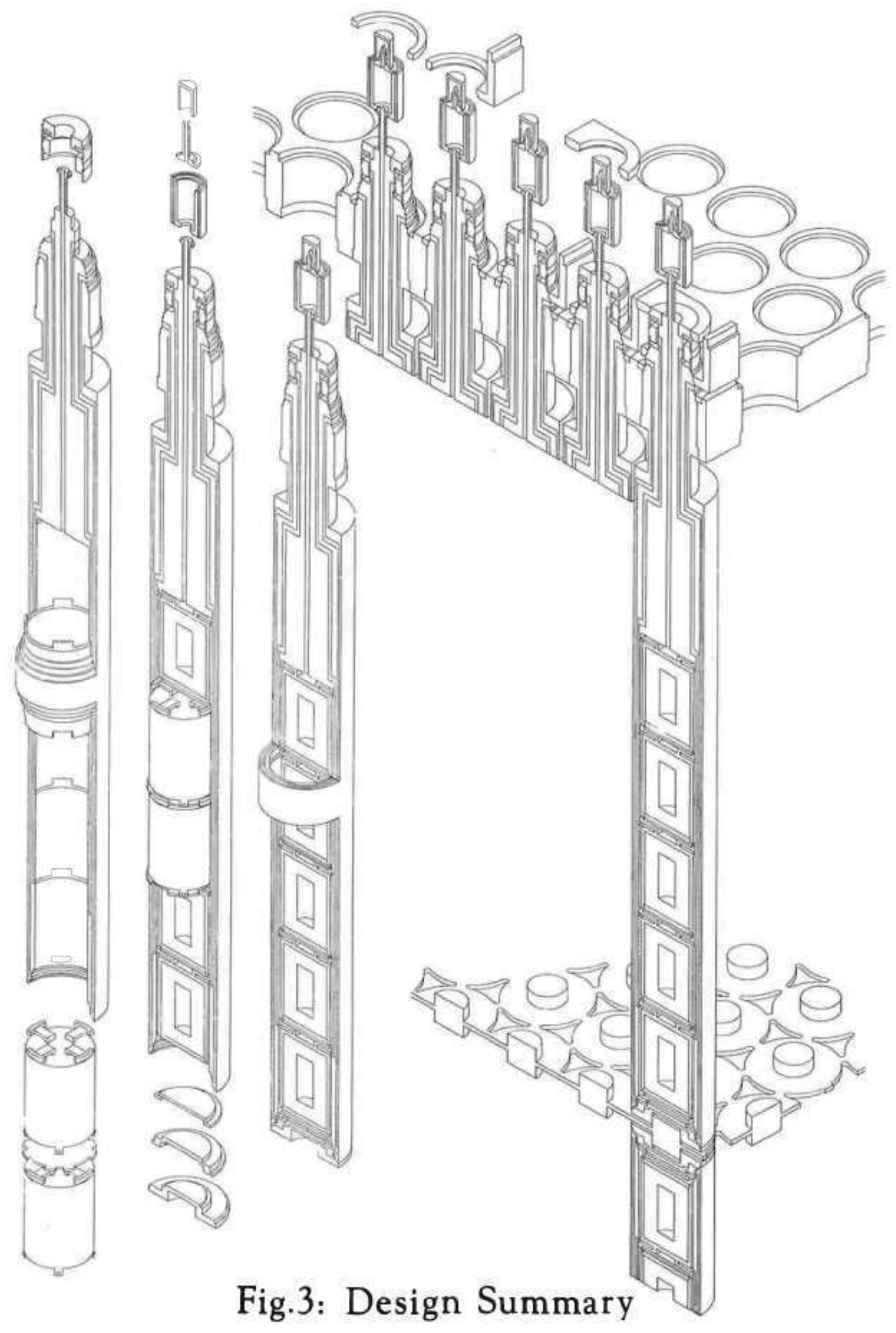

